\title{
Fibromyalgia of Women Who Gave Birth and Pregnancy Outcome Parameters
}

\author{
Maïmouna Coura Koné1, Nabé Alphonse Kambiré2, Koffi Kouakou1, Yapi Ahoua1 \\ ${ }^{1}$ Biology and Health Laboratory, Biology of Reproduction and Development Unit, Biosciences UFR, Félix Houphoüet-Boigny \\ University, Abidjan, Ivory Coast \\ ${ }^{2}$ Department of Psychology, Human and Social Sciences UFR, Félix Houphoüet-Boigny University, Abidjan, Ivory Coast \\ Email: kone.coura@ufhb.edu.ci,kambirenabe@gmail.com,kouakou.koffi@ufhb.edu.ci,yapi.ahoua@ufhb.edu.ci
}

How to cite this paper: Koné, M.C., Kambiré, N.A., Kouakou, K. and Ahoua, Y. (2022) Fibromyalgia of Women Who Given Gave Birth and Pregnancy Outcome Parameters. Open Journal of Epidemiology, 12, $1-11$.

https://doi.org/10.4236/ojepi.2022.121001

Received: October 11, 2021

Accepted: January 21, 2022

Published: January 24, 2022

Copyright $\odot 2022$ by author(s) and Scientific Research Publishing Inc. This work is licensed under the Creative Commons Attribution International License (CC BY 4.0).

http://creativecommons.org/licenses/by/4.0/

\begin{abstract}
Fibromyalgia syndrome (FS) is a common chronic disease characterized by widespread musculoskeletal pain in certain anatomic locations. Even though Fibromyalgia's prevalence and common symptoms in pregnant women are known, many issues related to the consequences of mother's fibromyalgia on pregnancy outcome have not been enough explored. The aim of this study is to highlight the relationship between fibromyalgia of women who gave birth and pregnancy outcome parameters like child delivery ways and newborn health. A first preliminary epidemiology study was thus carried out in the Bingerville general hospital. Our results showed that fibromyalgia was prevalent in women who gave birth as among 271 women who gave birth, $48.03 \%$ have fibromyalgia. A high frequency of women with fibromyalgia delivered by caesarian section (79.7\%). Apgar score indicated that newborns of the study have a good vitality as the score is higher than or equal to 7 for the majority of newborns. A large number of newborns were apparently in good health (160/184) compared to unhealthy newborns (24/184). We saw that a large frequency of unhealthy newborns were born from women with fibromyalgia $(14 / 24 ; 58.3 \%)$ while a low proportion of apparently in good health newborns were born from women with fibromyalgia. Healthy newborns have not been observed. All together, these data highlight the prevalence of fibromyalgia in women who gave birth and a relationship between fibromyalgia of mother, delivery modality and newborn health. However, in the situation of newborns' health, the link was not direct.
\end{abstract}

\section{Keywords}

Fibromyagia, Pregnancy, Delivery, Apgar, Newborn 


\section{Introduction}

Fibromyalgia syndrome (FS) is a common chronic disease characterized by widespread musculoskeletal pain in certain anatomic locations [1]. Chronic widespread pain during at least 3 months is the main symptom and many other comorbidities and symptoms are also present like fatigue, sleep disturbances, and other cognitive and somatic symptoms [2] [3].

FS is commonly observed rather in women than men with a proportion of 9:1; and the prevalence of FS in women ranges from 1\% up to 4\% [4] [5]. Generally, fibromyalgia affects women of reproductive age and these symptoms have consequences on menstruation, oral contraceptive usage, and breastfeeding duration, spontaneous abortion and pregnancy status [6]. Many studies described high prevalence of Fibromyalgia's symptoms in pregnant women [6] [7]. During pregnancy, fibromyalgia induced anxiety, maternal stress and depression that could disturb child outcome [8]. However, other studies [9] [10] (Marcus and Deodhard, 2011; Tulay et al., 2016) showed that FS has no negative effect on the outcome of pregnancy, parity, and duration of breastfeeding in women. The frequency and most common symptoms of fibromyalgia observed in pregnant women have also been described. These are low back pain, fatigue, pain severity, and higher levels of physical disability [11]. Even though Fibromyalgia's prevalence and common symptoms in pregnant women are known, many issues related to the consequences of mother's fibromyalgia on pregnancy outcome have not been enough explored. Specifically, further studies about the relationship between mother's fibromyalgia, fetus presentation, child delivery ways and newborn health are of great interest.

The aim of this study is to highlight the relationship between fibromyalgia of women who gave birth and pregnancy outcome parameters like child delivery ways and newborn health.

\section{Material and Methods}

\subsection{Study Site}

An epidemiological study was conducted to search for fibromyalgia in 271 women who came for child delivery in the gynecological unit of Bingerville Hospital.

\subsection{Study Time and Sample}

The investigation was conducted between 2018 and 2020. It took place at Bingerville General Hospital. The first of these (surveys) was held from July 1, 2018 to September 30, 2018 and enabled 111 women to be enrolled. The second survey took place in 2020 from September 29 to December 2 (3 months), which made it possible to recruit 160 women.

\subsection{Inclusion and Exclusion Criteria}

The general-purpose sampling technique is the one that was used for the conduct of the study. Indeed, the women coming for consultation in the Gyneco- 
logical and Pediatric Services with their newborns in the aforementioned periods (2018 and 2020) have been enrolled. To the latter, the research project and these objectives were explained to them in order to obtain their informed consent. Once their agreement was obtained, an interview was organized to collect their answers through questionnaires. In addition, access to their various medical records of the participants and their children made it possible to complete certain information. However, as participants came to consult for sexually transmitted infections, cases of rape, abortion were excluded from the study. As were those who expressed their refusal not to participate in the study once the objectives were presented. Among the 271 women enrolled during the two survey periods, only 184 gave us access to their baby's health record so that we could determine the Apgar score.

\subsection{Investigation}

Study was carried out by using a survey sheet that included:

$>$ the identity of the interviewee, their history, particularly medical, surgical, and gynecological pathologies;

a fibromyalgia screening questionnaire (FIQ): it measures evolution of fibromyalgia. It includes 10 questions answered by patients with "yes" or "no". Patients with fibromyalgia have at least 5 "yes" answers and patients with severe disease have at least 7 "yes" out of 10 ;

finding sore spots using the American College of Rheumatology (ACR) method. This method involves looking for at least 11 pain points out of 18 defined points. In practice, this corresponds to a palpation which makes it possible to whiten the nail;

$>$ delivery modality;

the vitality status of the newborns was analyzed by determining the Apgar score at the first and fifth minutes. The health status of newborns (unhealthy, apparently healthy and healthy) was then determined

\subsection{Data Processing}

Previously collected data on the survey forms were processed using IBM SPSS version 20 software. Variables are expressed in frequency and in percentage. Comparisons of variables between the diagnosis of fibromyalgia and the different situations by Pearson's chi-square test according to the theoretical numbers. With a p-value $<0.05$ the difference was considered statistically significant. For a $\mathrm{p}$-value $<0.01$ the difference was considered statistically very significant and for a $\mathrm{p}$-value $=0.000$ the difference was considered highly significant.

\section{Results}

\subsection{Fibromyalgia Prevalence in Women Who Have Given Birth}

Among women who had already given birth, 131/271 tested positive for fibromyalgia (48.3\%) (Table 1). 
Table 1. Diagnosis of fibromyalgia in women who have given birth fibromyalgia.

\begin{tabular}{lcccc}
\hline & \multicolumn{2}{c}{ Fibromyalgia diagnosis test } & \multirow{2}{*}{ Total } \\
\cline { 2 - 3 } & Yes & No & \\
\hline Women having given birth & $131(48.3 \%)$ & $140(51.7 \%)$ & 271 \\
\hline
\end{tabular}

\subsection{Maternal Fibromyalgia and Delivery Modalities}

A high frequency of women who gave birth by caesarean section, $47 / 68$ (79.7\%) were diagnosed with fibromyalgia (Table 2) with a high significative difference $(\mathrm{p}<0.001)$ compared to women without fibromyalgia $(12 / 68 ; 20.3 \%)$. In the situation of vaginal delivery, the proportions of women with fibromyalgia (82/202; $40.6 \%)$ are lower than that of women without fibromyalgia (120/202; 59.4\%). The difference is highly significant $(\mathrm{p}<0.001)$. A similar situation has been observed in the situation vaginal delivery using a vacuum cup. Indeed, the proportion of women who gave birth by this modality and that have fibromyalgia (2/14; $20 \%$ ) was lower than that of women without fibromyalgia $(8 / 14 ; 80 \%)$ with a highly significant difference $(\mathrm{p}<0.001)$. These findings suggested a relationship between fibromyalgia of mother and the delivery modality, notably in the specific situation of caesarian delivery.

\subsection{Newborn Health}

\subsubsection{Distribution of Newborns in the Study According to the Apgar Score}

The results showed the live 164 newborns or $89.1 \%$ had an Apgar score greater than 7 at the first minute of birth, while 20 newborns had a score less than or equal to 7 , i.e. a frequency of $10.9 \%$. By the fifth minute of birth, 174 newborns had an Apgar score greater than 7, or a frequency of $94.6 \%$. On the contrary, 10 newborns had an Apgar score of 7, a rate of 5.4\% (Table 3). These results show that globally, a large proportion of newborns has an Apgar score greater than or equal to 7, suggesting that the majority of newborns have good vitality.

\subsubsection{Distribution of Newborns in the Study According to Their State of Health}

In this part of the study, we were able to record information only from 184 babies. Indeed, among the 271 women enrolled, only 184 agreed to gave us access to their child's health record to collect information relating to their health. We saw that a high proportion of newborns is apparently in good health $(160 / 184$; $89 \%)$ while a low proportion of newborns was unhealthy $(24 / 184 ; 13.04 \%)$ (Table 4). Healthy newborns have not been found because no baby showed an Apgar score equal to 10. Thus, majority of newborns in the study is apparently healthy.

\subsubsection{Relationship between Maternal Fibromyalgia and Newborn Health Status}

Among the 184 newborns of the study (Table 5), apparently good health newborns are majority observed $(\mathrm{n}=160)$ compared to unhealthy newborns $(\mathrm{n}=$ 
24). However, the results showed that among unhealthy newborns, $14 / 24$ (58.3\%) were born of women with fibromyalgia while 10/24 newborns were born of women without fibromyalgia with a highly significant difference $(\mathrm{p}<0.001)$. In the situation of apparently healthy newborns, a high frequency has been observed for women without fibromyalgia (123/160; 76.9\%) compared to proportion of newborns that were born of women with fibromyalgia (37/160;23.1\%). The difference observed is highly significant $(\mathrm{p}<0.001)$. These data showed that there could be a relationship between fibromyalgia of mother and newborn health.

Table 2. Relationship between fibromyalgia and delivery modalities. Highly significant Pearson chi-square test for $\mathrm{p}$-value $<0.001$.

\begin{tabular}{cccccc}
\hline & \multicolumn{2}{c}{ Fibromyalgia Diagnosis test $\mathbf{n}(\%)$} & $X^{2}$ & \multirow{2}{*}{ Potal } \\
\cline { 2 - 4 } \cline { 2 - 3 } & Yes & No & & & \\
\hline Vaginal delivery & $82(40.6)$ & $120(59.4)$ & 31.24 & 0.000 & 202 \\
Caesarian & $47(79.7)$ & $12(20.3)$ & & & 68 \\
Suction cup delivery & $2(20)$ & $8(80)$ & & 14 \\
\hline
\end{tabular}

Table 3. Distribution of newborns in the study according to the Apgar score at the first minute and the fifth minute after birth.

\begin{tabular}{ccc}
\hline Apgar Score & Number (n) & Percentage (\%) \\
\hline First minute & & \\
\hline Apgar $\leq 7$ & 20 & 10.9 \\
Apgar $>7$ & 164 & 89.1 \\
\hline Fifth minute & & 5.4 \\
\hline Apgar $=7$ & 10 & 94.6 \\
Apgar $>7$ & 174 & \\
\hline
\end{tabular}

Table 4. Distribution of newborns in the study according to their state of health.

\begin{tabular}{ccc}
\hline Unhealthy newborn & Apparently good health & Healthy newborn \\
\hline $\begin{array}{c}\text { Apgar } \leq 8 \\
\mathrm{n}(\%)\end{array}$ & $\begin{array}{c}\text { Apgar between } 9 \text { and } 10 \\
\mathrm{n}(\%)\end{array}$ & $\begin{array}{c}\text { Apgar }=10 \\
\mathrm{n}(\%)\end{array}$ \\
$24(13.04 \%)$ & $160(86.95 \%)$ & $0(0 \%)$
\end{tabular}

Table 5. Relationship between maternal fibromyalgia and newborn health status. Highly significant Pearson chi-square test for p-value $<0.001$.

\begin{tabular}{cccccc}
\hline & \multicolumn{2}{c}{ Mother fibromyalgia diagnosis } & $X^{2}$ & P-value & \multirow{2}{*}{ Total } \\
\cline { 2 - 5 } & Yes & No & & \\
\hline Unhealthy newborn & $14(58.3 \%)$ & $10(41.3 \%)$ & & $24(100 \%)$ \\
Apparently good health & $37(23.1 \%)$ & $123(76.9 \%)$ & 12.91 & 0.000 & $160(100 \%)$ \\
Healthy newborn & 00 & 00 & & 00 \\
& Total & & & 184 \\
\hline
\end{tabular}




\section{Discussion}

The aim of this study was to highlight the relationship between fibromyalgia of women who gave birth and pregnancy outcome parameters like child delivery ways and newborn health. To do this, we first looked for fibromyalgia in 271 women who gave birth in the general hospital of Bingerville, then analyzed the relationship between the mother's fibromyalgia and various parameters such as the modality of delivery and the state of newborn health. All the data showed that fibromyalgia was prevalent in women who gave birth and the state of health of the mother was associated with the modality of delivery and the health of the newborn. To our knowledge, prevalence of fibromyalgia in pregnant women is poorly documented in Ivory Coast. Thus, our observations provided preliminary information on the various consequences of maternal fibromyalgia on the outcome of the pregnancy particularly in Ivory Coast.

We observed a frequency of 131/271 women who gave birth (48.3\%) diagnosed with fibromyalgia that were lightly low compared to women without fibromyalgia (141/271; 51.7\%). This low observed frequency could be linked to the small sample size. However, we were unable to identify when fibromyalgia appears. Although the proportions observed in our study are low, these data are in agreement with the work of several authors [7] [11] [12] who reported the prevalence of fibromyalgia in pregnant women.

A relationship between fibromyalgia of mother and the modality of delivery has been observed. Caesarean delivery is predominantly represented in all women diagnosed with fibromyalgia compared to other delivery modalities. In addition, this proportion $(47 / 68 ; 79.7 \%)$ is significantly higher $(\mathrm{p}<0.001)$ than the proportion of women negatively diagnosed with fibromyalgia who gave birth by caesarean section $(12 / 68 ; 20.3 \%)$. These data show that maternal fibromyalgia can influence the way of delivery. Our results are in agreement with data from [12] which showed a high prevalence of Caesarean delivery in women with fibromyalgia. However, these authors used a sample larger than the sample of our study. In a normal delivery, the contractility of the myometrium is improved as a result of increased estrogen level or estrogen/progesterone ratio. Changes in other hormones such as cortisol should also be considered [13] [14]. This contractility of the myometrium as well as the opening of the cervix are decisive for achieving a birth by vaginal way. Caesarean section delivery, on the other hand, is indicated when the mother has difficulty delivering normally vaginally or if this method of delivery may present risks to the mother or child. We can hypothesize that fibromyalgia positive patients would have decreased myometrial contractility or blocked cervical opening, thus causing risk for baby. Caesarean section may also be indicated in several situations, including labor dystocia, abnormal or indeterminate (formerly, nonreassuring) fetal heart rate tracing, fetal malpresentation, multiple gestation, and suspected fetal macrosomia non reassuring fetal status, arrest of dilation, preeclampsia, arrest of descent, maternal-fetal indications, and other obstetric indications (e.g., cord prolapse, placen- 
ta previa) [15] [16]. We did not investigate the reasons for the caesarean section in these women. Thus, it was difficult to establish a direct link between fibromyalgia and these indications. In addition we bearn in mind that it was possible that these mothers have themselves expressed the desire to give birth by cesarean section independently of the fibromyalgia diagnosis.

Apgar scores include color, heart rate, reflexes, muscle tone, and respiration and allow to assess for signs of hemodynamic compromise such as cyanosis, hypoperfusion, bradycardia, hypotonia, respiratory depression, or apnea [17]. With Apgar score, it was not easier to know the reel state of health of newborns because this score was based on simple observations of some parameters. A large percentage of newborns recorded in this study had an Apgar score greater than or equal to 7 at the first and fifth minutes. A small portion of the newborns had an Apgar score below 7. However, the repartition of newborns according to health status showed that majority of newborns was apparently in good health $(160 / 184 ; 89 \%)$ while a low proportion of newborns was unhealthy $(24 / 184$; 13.04\%). Any newborns in good health have been observed because any baby showed an Apgar score equal to 10. However, we bear in mind that the Apgar score is not sufficient to testify the real state of health of the children. Additional tests could confirm or refute the results of the Apgar score. This data only indicated that the majority of newborns in this study had good vitality and were majority apparently in good health but the real health state and how fibromyalgia affected him during pregnancy were difficult to highlight.

A relationship between fibromyalgia of mother and newborn health could however be established. Indeed, among 24 unhealthy newborns 14/24 (58.3\%) have been born from women with fibromyalgia while 10/24 (41.3\%) have been born from women without fibromyalgia $(\mathrm{p}<0.001)$. Although, it was difficult to know that if this relationship was direct as these 24 unhealthy newborns were minority compared to 160 apparently in good health newborns. Even in this last situation, only a low proportion of newborns were born from women with fibromyalgia $(37 / 160 ; 23.1 \%)$ compared to newborns that were born from women without fibromyalgia $(123 / 160 ; 76.9 \%)(\mathrm{p}<0.001)$. The results of our study raise questions about the existence of a possible relationship between the state of health of the mother and that of the child. But, our sampling didn't allow to establish a direct relationship between maternal fibromyalgia and newborn health contrary to data from [12]. However, it is important to note that these authors analyzed the percentage of premature infants born to mothers with fibromyalgia, parameter which was not analyzed in our study.

This prospective study made it possible to assess the prevalence of FM, as a chronic painful condition, in women. The results of this study cannot be generalized to all Ivorian populations due to the absence of general population prevalence data of FM in Ivory Coast. The prevalence data of FM available in Côte d'Ivoire come from the psychiatric community [18].

In addition, given the number of participants recruited, an extrapolation of 
the results is difficult. However, the conduct of other studies integrating a larger number of participants could allow an extrapolation to the level of the general population.

\section{Conclusion and Perspectives}

The aim of this study is to highlight the relationship between fibromyalgia women who gave birth and pregnancy outcome parameters like child delivery ways and newborn health. Fibromyalgia is prevalent in women who gave birth related to child delivery ways and newborn health. Particularly, delivery by Caesarian way was prevalent in women with fibromyalgia compared to normal vaginal delivery. Newborns had a good vitality based on their Apgar score. But, a large number of unhealthy newborns that were born from women with fibromyalgia have been observed even if they represent a minority compared to apparently in good health newborns. Thus, direct relationship between fibromyalgia and newborn health was difficult to be established based on our sampling. It could be of great interest to increase the number of mother sampling with fibromyalgia in this study. Further investigation on the mechanism involved in delivery way and newborn health could be relevant. It could be necessary to introduce some other parameters like the rate to better analyse the relationship between fibromyalgia and pregnancy outcome.

\section{Conflicts of Interest}

The authors declare no conflicts of interest regarding the publication of this paper.

\section{References}

[1] Clauw, D.J. (2001) Elusive Syndromes: Treating the Biologic Basis of Fibromyalgia and Related Syndromes. Cleveland Clinic Journal of Medicine, 68, 830, 832-834. https://doi.org/10.3949/ccjm.68.10.830

[2] Laroche, F. (2019) Fibromyalgie [Fibromyalgia]. La Revue du Praticien, 69, 649-651.

[3] Bair, M.J. and Krebs, E.E. (2020) Fibromyalgia. Annals of Internal Medicine, 172, ITC33-ITC48. https://doi.org/10.7326/AITC202003030

[4] Yunus, M.B. (2001) The Role of Gender in Fibromyalgia Syndrome. Current Rheumatology Reports, 3, 128-134. https://doi.org/10.1007/s11926-001-0008-3

[5] Clauw, D.J. (2009) Fibromyalgia: An Overview. The American Journal of Medicine, 122, S3-S13. https://doi.org/10.1016/j.amjmed.2009.09.006

[6] Ostensen, M., Rugelsjøen, A. and Wigers, S.H. (1997) The Effect of Reproductive Events and Alterations of Sex Hormone Levels on the Symptoms of Fibromyalgia. Scandinavian Journal of Rheumatology, 26, 355-360. https://doi.org/10.3109/03009749709065698

[7] Saa'd, S., Many, A., Jacob, G. and Ablin, J.N. (2013) High Prevalence of Fibromyalgia Symptoms among Healthy Full-Term Pregnant Women. Rheumatology International, 33, 1555-1560. https://doi.org/10.1007/s00296-012-2627-6

[8] Genç, H., Atasever, M., Duyur Çakit, B., Seval, M. and Koç, A. (2017) The Effects of 
Fibromyalgia Syndrome on Physical Function and Psychological Status of Pregnant Females. Archives of Rheumatology, 32, 129-140.

https://doi.org/10.5606/ArchRheumatol.2017.6028

[9] Zioni, T., Buskila, D., Aricha-Tamir, B., Wiznitzer, A. and Sheiner, E. (2011) Pregnancy Outcome in Patients with Fibromyalgia Syndrome. The Journal of Maternal-Fetal \& Neonatal Medicine, 24, 1325-1328.

https://doi.org/10.3109/14767058.2010.551152

[10] Tulay, K.T., Emrullah, T., Aydin, A. and Ciledag, O.F. (2016) The Effect of Fibromyalgia Syndrome to Gravidity, Parity and Duration of Breastfeeding; A Prospective Study from Turkey. Pakistan Journal of Medical Sciences, 32, 545-549.

https://doi.org/10.12669/pjms.323.9574

[11] Genç, H., Atasever, M., Duyur Çakit, B., Seval, M. and Koç, A. (2017) The Effects of Fibromyalgia Syndrome on Physical Function and Psychological Status of Pregnant Females. Archives of Rheumatology, 32, 129-140. https://doi.org/10.5606/ArchRheumatol.2017.6028

[12] Magtanong, G.G., Spence, A.R., Czuzoj-Shulman, N. and Abenhaim, H.A. (2019) Maternal and Neonatal Outcomes among Pregnant Women with Fibromyalgia: A Population-Based Study of 12 Million Births. Journal of Maternal-Fetal and Neonatal Medicine, 32, 404-410. https://doi.org/10.1080/14767058.2017.1381684

[13] Mastorakos, G., Pavlatou, M.G. and Mizamtsidi, M. (2006) The Hypothalamic-Pituitary-Adrenal and the Hypothalamic-Pituitary-Gonadal Axes Interplay. Pediatric Endocrinology Reviews, 3, 172-181.

[14] Pednekar, D.D., Amin, M.R., Azgomi, H.F., Aschbacher, K., Crofford, L.J. and Faghih, R.T. (2020) Characterization of Cortisol Dysregulation in Fibromyalgia and Chronic Fatigue Syndromes: A State-Space Approach. IEEE Transactions on Biomedical Engineering, 67, 3163-3172. https://doi.org/10.1109/TBME.2020.2978801

[15] Barber, E.L., Lundsberg, L.S., Belanger, K., Pettker, C.M., Funai, E.F. and Illuzzi, J.L. (2011) Indications Contributing to the Increasing Cesarean Delivery Rate. Obstetrics \& Gynecology, 118, 29-38. https://doi.org/10.1097/AOG.0b013e31821e5f65

[16] Caughey, A.B., Cahill, A.G., Guise, J.-M. and Rouse, D.J. (2014) Safe Prevention of the Primary Cesarean Delivery. American Journal of Obstetrics and Gynecology, 210, 179-193. https://doi.org/10.1016/j.ajog.2014.01.026

[17] Simon, L.V., Hashmi, M.F. and Bragg, B.N. (2021) APGAR Score. StatPearls Publishing, Treasure Island.

[18] Kambiré, N.A., Yapi, A., Ackah, Y.M.E. and Yéo, T. (2018) Psychosocial Factors of Fibromyalgia in Newbies Patients with Major Depressive Disorder. European Journal of Social Sciences, 57, 139-150. 


\section{Appendix}

\section{SURVEY}

\section{I/IDENTIFICATION OF MOTHER}

Date: .$/ 20$

Contact:

Date of birth:

First and last name: Age:

Place of de birth: ; Weigt

$\mathrm{Kg}$ HTA: ...... Sexe: ...

Conditions of birth: Maternity $\square$ Outside of maternity $\square$;

Sibling rank: Mother .............. Father: .............. Ethnicity:

Profession:

Do you practice the other sport? How many time a week?

Location:

Reason of consultation.

Observations and diagnosis:

Received treatment.

II/ANTECEDENTS

Do you have chilfren ? Yes $\square$ No $\square$........If yes, how many?

Have you ever given birth to a stillborn child? Yes $\square$ No $\square$

Have you had gynaecological surgery? (fibroma, EUG, ovarian cyst)?

Yes $\square$ No $\square$

Have you ever had a miscarriage? Yes $\square$ No $\square$. If yes, how many times? ...... Type of breastfeeding: Milk $\square$ Breast $\square$ Mixed $\square$

Do you use contraceptives? Yes $\square$ No $\square$; I yes, what type?

How long have you been using it?

Delivery: Vaginal delivery $\square$ Caesarean $\square$ Other

Do you consult a gynaecologist? Yes $\square$ No $\square$; If yes, how many times?

III/PATHOLOGICAL ASSOCIATIONS

Do you have menstrual problems?

Do you have any pathologies of the uterus? (cervical cancer, uterine cancer, endometriosis, endometritis)

Do you have any pathologies in the ovaries?

Do you have any vaginal or vulvar pathologies?

Do you have any cervical pathologies? (cyst)

IV/FIBROMYALGIA RAPID SCREENING TOOL OF PERROT

You have been suffering from joint, muscle or tendon pain for the past 3 months at least. Please answer this questionnaire in order to help your doctor evaluate your pain and symptoms more effectively.

\section{ITEMS}

I have pain all over my body.

My pain is accompanied by a continuous and very unpleasant general fatigue. 


\section{Continued}

My pain feels like burns, electric shocks or cramps.

My pain is accompanied by other unusual sensations throughout my body such as pins and needles, tingling or numbness.

My pain is accompanied by other health problems such as digestive problems, urinary problems, headaches or restless legs.

My pain has a significant impact on my life, particularly on my sleep and my ability to concentrate, making me feel slower generally.

\section{V/INFORMATION ABOUT THE CHILD}

First name and last name:. Age:. Sexe:...

Place of birth: Weigt...... Kg; Taille:....Cm

Conditions of birth: Maternity $\square$ Outside maternity $\square$

Apgar score 1st minute: less than $7 \square$ greater than 7

5th minute Apgar score: less than $7 \square$ greater than 7

Does your child have the hump? Yes $\square$ No

Sibling rank: Mother...

Father.

Reason of consultation

Observations and diagnosis:

Received treatment:

Did your child have any health problems after giving birth ? Yes $\square$ No

If yes, please specify:

How many hospital visits with the child have you made in the last 3 months? 1 à

$2 \square 3$ à $5 \square 6$ et plus

Children's sleep: little sleep $\square$ sleep a lot

Nutrition: Eat little $\square$ Eat normally

Does your child complain of joint pain? Yes $\square$ No $\square$ 